\title{
Innovative software simulation techniques to design specular curved baffle designs in ground- and space- based telescopes
}

Ding, Yitian, Bushroe, Frederick, Pau, Stanley, Gauvin, Michael

Yitian Ding, Frederick Bushroe, Stanley Pau, Michael Gauvin, "Innovative software simulation techniques to design specular curved baffle designs in ground- and space-based telescopes," Proc. SPIE 11103, Optical Modeling and System Alignment, 111030J (11 September 2019); doi: 10.1117/12.2535754

SPIE Event: SPIE Optical Engineering + Applications, 2019, San Diego, California, United States 


\title{
Innovative software simulation techniques to design specular curved baffle designs in ground- and space-based telescopes
}

\author{
Yitian Ding ${ }^{\mathrm{a}}$, Frederick Bushroe ${ }^{\mathrm{b}}$, Stanley Pau ${ }^{\mathrm{a}}$, Michael Gauvin ${ }^{\mathrm{c}}$, \\ ${ }^{\mathrm{a} J a m e s}$ C. Wyant College of Optical Sciences, University of Arizona (United States), ${ }^{b}$ INOV Inc.

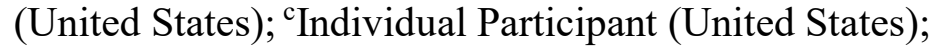

\begin{abstract}
We investigated several curved vane baffle designs coated with specular black paint as an inexpensive manufacturing alternative to traditional diffuse baffles vanes to reduce stray light and heat due to absorption in a standard Cassegrain telescope design configuration. The heat absorption is a very large problem in infrared systems and the specular designs solve this part of the problem. Our study involved simulating two different types of baffle systems, diffuse and specular painted vanes on the main barrel baffle. The first type of baffle consisted of evenly and non-evenly spaced diffusely black coated straight planar vanes on the main barrel baffle and a second type using specular black paint on curved vanes. TracePro, a stray light simulation software from Lambda Research Corporation, was used to simulate and compare each of the nine baffle systems for stray light rejection. The diffuse black painted straight vane baffle design was used as the baseline design to compare results to the other eight designs. In all designs except for the baseline design, TracePro's local downhill simplex optimization method was used to optimize each vane curvature and spacing in the main barrel baffle to reject incoming stray light. These curved vanes were designed to reject stray light back out of the main barrel baffle rather than to be absorbed by diffuse black paint.
\end{abstract}

Keywords: Stray Light, Specular Baffles, Diffuse Baffles, Baffles, Vanes, TracePro, Simulation, Curved Vanes, Ray Tracing Software, Scatter

\section{INTRODUCTION}

Forty years ago, diffuse coated, straight, evenly spaced vanes were the norm for a main barrel baffle used in a Cassegrain telescope to reject stray light. Dr. Robert Breault pioneered a new type of vane setup in the Hubble space telescope with unevenly spaced vanes which reduced the number of vanes, the weight of the main baffle, and reduced stray light reaching the detector better than the older straight evenly spaced vane configuration. This paper investigates three vane variations, curved vanes, varying depth of vanes and specular painted vanes in a Cassegrain telescope system. A total of 9 vane configurations with both diffuse and specular painted main barrel baffles were simulated and their PSNIT was calculated. We started with a baseline design of the type used forty year ago which uses evenly spaced vanes and then optimized and simulated 8 other designs using both diffuse and specular painted vanes with uneven spacing, varying depths and curved vanes. There are 6 diffuse coated designs and 3 specular coated designs. Table 1 gives the details for each vane configuration.

\subsection{Key Terminology}

Stray light is light in an optical system, which was not intended in the design. The light may be from the intended source, but follow paths other than intended, or it may be from a source other than the intended source. ${ }^{1}$

PSNIT is the Point Source Normalized Irradiance Transmittance and the equation used is $E_{\text {det }} / E_{\text {src }}$, where $E_{\text {det }}$ and $E_{\text {src }}$ are the irradiance values at the detector and at the source.

Vanes - Thin disks that are placed inside baffles to block or reject stray light. For this paper, vanes can be either vertical structures or curved vertical structures.

Baffle - Cylindrical tubes to hold vanes and block incoming stray light.

Optical Modeling and System Alignment, edited by Mark A. Kahan, José Sasián,

Richard N. Youngworth, Proc. of SPIE Vol. 11103,111030J · (c) 2019 SPIE

CCC code: $0277-786 \mathrm{X} / 19 / \$ 21 \cdot$ doi: $10.1117 / 12.2535754$ 
A Cassegrain telescope is a combination of a primary concave mirror and a secondary convex mirror, which is often used in optical telescopes and radio antennas; the main characteristic consists of optical path folding back onto itself, relative to the optical system's primary mirror entrance aperture. This design puts the focal point at a convenient location behind the primary mirror, and the convex secondary adds a telephoto effect, creating a much longer focal length in a mechanically short system.

Specular Baffle - Baffle that is coated with partially reflective, partially diffuse and absorbing paint.

Diffuse Baffle - Baffle that is coated with a paint that is mostly absorbing with some diffuse scattering properties.

TracePro $^{\circledR}$ - Commercial stray light analysis software manufactured by Lambda Research Corporation.

ABg scattering model - The ABg BSDF model is a modified inverse-power-law model. It has the form

$$
B S D F\left(\left|\vec{\beta}-\vec{\beta}_{0}\right|\right)=\frac{A}{B+\left|\vec{\beta}-\vec{\beta}_{0}\right|^{g}}
$$

where the $\beta$ and $\beta_{0}$ vectors are from the Harvey-Shack BSDF model. In this model, the beta vector is the projection of a unit vector in the scattering direction onto the tangent plane, and the $\beta_{0}$ vector is a projection of the unit vector in the specular direction onto the tangent plane. $\mathrm{A}, \mathrm{B}$, and $\mathrm{g}$ are fitting parameters.

Hot Areas or Objects - Rays that strike any object or surface directly from an incoming ray bundle. These rays have $100 \%$ of their starting energy in a simulation program.

Critical Areas or Objects - A critical object is any object or surface that is seen from the detector, including objects that are seen as images in mirrors and lenses. Critical objects are important in stray light analysis because $100 \%$ of the stray light comes from these objects. If the detector cannot see an object, then no stray light comes from it. ${ }^{2}$

Importance sampling - is a variance reduction technique to direct light at critical objects in stray light analysis to provide better sampling for rays to reach the detector.

\subsection{Vane Configurations}

Table 1. Vane configuration information for the nine different baffle designs investigated in this paper

\begin{tabular}{|l|l|l|}
\hline \multicolumn{1}{|c|}{ Configuration name } & \multicolumn{1}{|c|}{ Coating } & \multicolumn{1}{c|}{ Design } \\
\hline Baseline & Diffuse Black & Seven evenly spaced straight vanes \\
\hline Diffuse conventional 7V & Diffuse Black & Seven unevenly spaced straight vanes \\
\hline Diffuse conventional 8V & Diffuse Black & Eight unevenly spaced straight vanes \\
\hline Diffuse Var-Dist 20Deg & Diffuse Black & $\begin{array}{l}\text { Seven unevenly spaced straight vanes optimized } \\
\text { to reduce stray light at 20 degrees }\end{array}$ \\
\hline Diffuse Var-Dist 40Deg & Diffuse Black & $\begin{array}{l}\text { Seven unevenly spaced straight vanes optimized } \\
\text { to reduce stray light at 40 }\end{array}$ \\
\hline Diffuse curved & Diffuse Black & Seven unevenly spaced curved vanes \\
\hline Specular curved & Specular Black & Eight unevenly spaced curved vanes \\
\hline Specular flat & Specular Black & Eight unevenly spaced flat vanes \\
\hline Specular Stavroudis & Specular Black & $\begin{array}{l}\text { Stavroudis design scaled to fit our Cassegrain } \\
\text { system to verify our specular vane designs }\end{array}$ \\
\hline
\end{tabular}




\subsection{Baffle Designs}

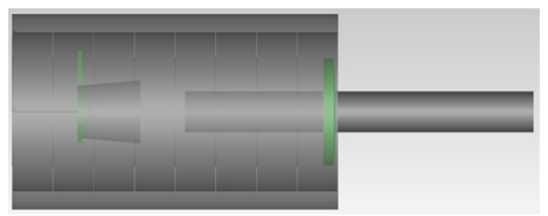

Diffuse baseline

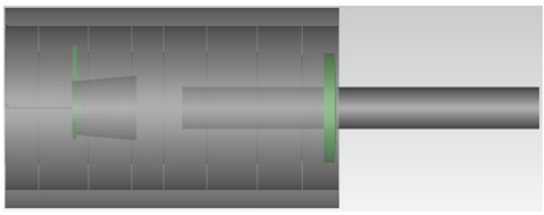

Diffuse Var-Dist 40Deg

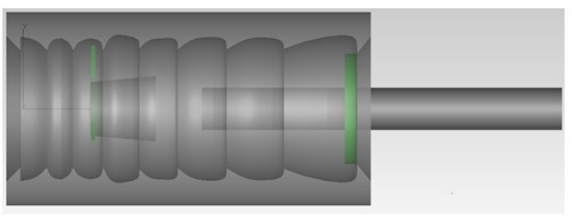

Diffuse curved

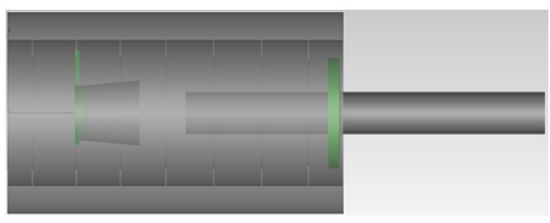

Diffuse conventional 7V

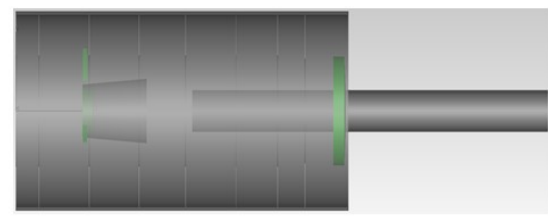

Diffuse Var-Dist 20Deg

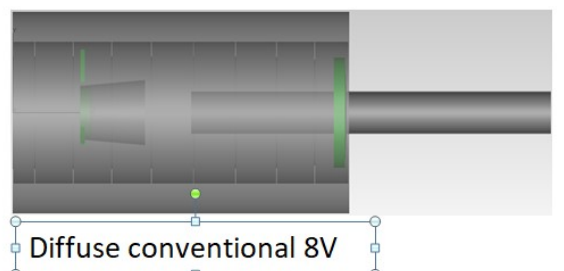

Figure 1. Diffuse baffle designs used in this paper as described in Table 1

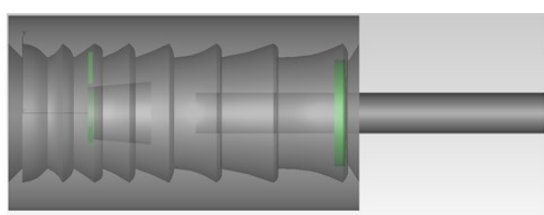

Specular curved

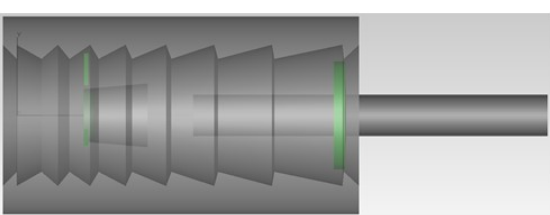

Specular flat

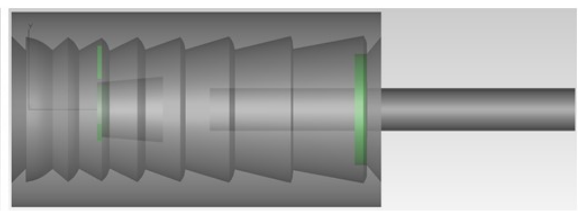

Specular Stavroudis

Figure 2. Specular baffle designs used in this paper as described in Table 1.

\subsection{Diffuse and Specular Paint definitions used}

The definitions of the diffuse and specular black paints used in the nine vane configurations are as follows:

Diffuse black paint: 97\% absorption, 3\% diffuse scattering ( $\mathrm{ABg}$ model: $\mathrm{A}=0.019, \mathrm{~B}=1, \mathrm{~g}=0$ )

Specular black paint: $40 \%$ absorption, $40 \%$ specular reflection, $20 \%$ diffuse scattering (ABg model: $\mathrm{A}=0.127, \mathrm{~B}=1, \mathrm{~g}$ $=0)$

\section{OPTICAL DESIGN OF THE CASSEGRAIN TELESCOPE}

The optical description of the Cassegrain telescope was created in the Zemax OpticStudio software from Zemax, LLC. The lens prescription is shown below for the mirror design used for all nine vane configuration simulations in Figure 3. Figure 4 shows a standard layout of the system with rays tracing from the center and the edge of the field of view (FoV).

\section{Hand-Made Telescope and Primary \& Secondary Baffle Design Procedure}

\begin{tabular}{|c|c|c|c|c|c|c|c|c|c|c|c|c|}
\hline \multicolumn{3}{|c|}{ Surf:Type } & \multirow[t]{2}{*}{ Comment } & \multirow{2}{*}{$\begin{array}{l}\text { Radius } \\
\text { Infinity }\end{array}$} & \multirow{2}{*}{$\begin{array}{l}\text { Thickness } \\
\text { Infinity }\end{array}$} & \multirow[t]{2}{*}{ Material } & \multirow[t]{2}{*}{ Coating } & \multirow{2}{*}{$\begin{array}{r}\text { Semi-Diameter } \\
\text { Infinity }\end{array}$} & \multirow{2}{*}{$\begin{array}{c}\text { Chip Zone } \\
0.000\end{array}$} & \multirow{2}{*}{$\begin{array}{r}\text { Mech Semi-Dia } \\
\text { Infinity }\end{array}$} & \multirow{2}{*}{$\begin{array}{l}\text { Conic } \\
0.000\end{array}$} & \multirow{2}{*}{$\begin{array}{c}\text { TCE } \times 1 \mathrm{1E}-6 \\
0.000\end{array}$} \\
\hline 0 & OBJECT & Standard - & & & & & & & & & & \\
\hline 1 & (aper) & Standard & & Infinity & 300.000 & & & 52.309 & 0.000 & 53.618 & 0.000 & 0.000 \\
\hline 2 & STOP (aper) & Standard $\mathbf{v}$ & & -800.000 & $-226.816 \mathrm{~V}$ & MIRROR & & 51.007 & 0.000 & 51.000 & $-0.492 \mathrm{~V}$ & 0.000 \\
\hline 3 & (aper) & Standard $=$ & & $-582.862 \mathrm{~V}$ & $426.816 \mathrm{~V}$ & MIRROR & & $24.000 \mathrm{U}$ & 0.000 & 24.000 & 0.000 & 0.000 \\
\hline 4 & IMAGE & Standard- & & Infinity & - & & & 4.329 & 0.000 & 4.329 & 0.000 & 0.000 \\
\hline
\end{tabular}

Figure 3. OpticStudio lens prescription for the Cassegrain telescope used in this paper as the optical design. 


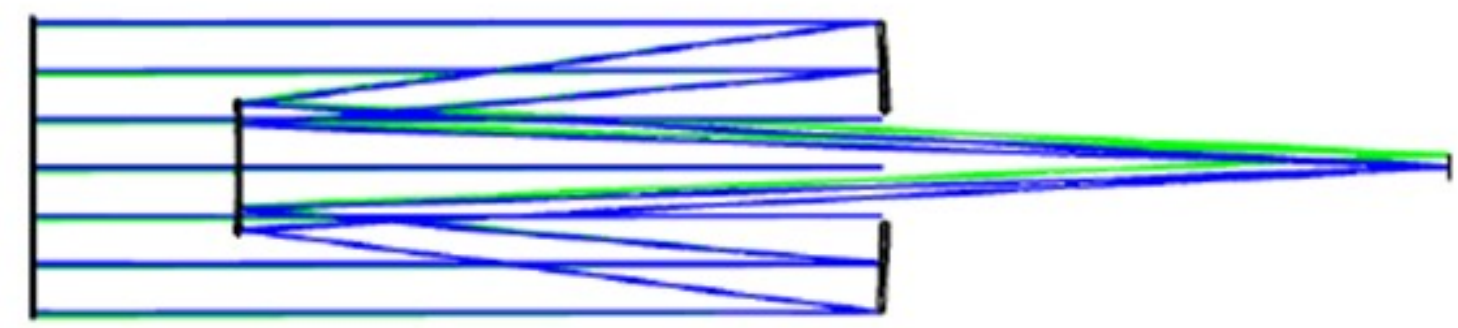

\section{FoV: 0.25 degree}

\begin{tabular}{|c|c|}
\hline \multicolumn{2}{|c|}{ Layout } \\
\hline $\begin{array}{l}\text { CASSECRAIN RITOHEY-CHRTIEN } \\
5 / 1 / 2017 \\
\text { Total Ax1al Leroth: } 500.00003 \mathrm{mn}\end{array}$ & $\begin{array}{c}\text { Zenax } \\
\text { Zenax opticstudio } 15.5 \text { SP2 }\end{array}$ \\
\hline & 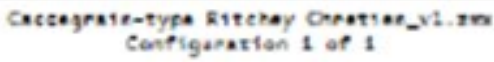 \\
\hline
\end{tabular}

Figure 4. Mirror design of the Cassegrain telescope used in this paper for all vane configuration simulations with rays traced.

\section{DIFFUSE BAFFLE DESIGNS}

There are six different diffuse vane baffle designs. Each design was created to investigate one of the following, evenly spaced baffles, curved, variable optimized to reduce stray light particularly for the 20 degrees incoming angle and one for the 40 degrees incoming angle, conventional with seven and eight unevenly spaced vanes.

\subsection{Design of the Conventional Seven Vane Diffuse Baseline System with an Equal Spacing}

The baseline vane design is made up of seven vanes with equal spacing. The last larger disk at the end is the back of the main baffle which closes the cylindrically shaped main baffle. The inner radius of all seven vanes is $75.89 \mathrm{~mm}$. The end point of the vane is $51 \mathrm{~mm}+\tan \left(0.25^{\circ}\right) \times 312 \mathrm{~mm}=52.4 \mathrm{~mm}$ to the optical axis, which allows just the ray at the edge of the FoV to hit the edge of the primary mirror. The spacing is determined in such a way that incoming rays from the source, "hot rays", can only see the back area of the main baffle and are separate from the areas that are seen by the detector which we label "critical rays". Figure 5 shows the vane profile. Figure 6 shows the dimensions of the baffle and the vanes.

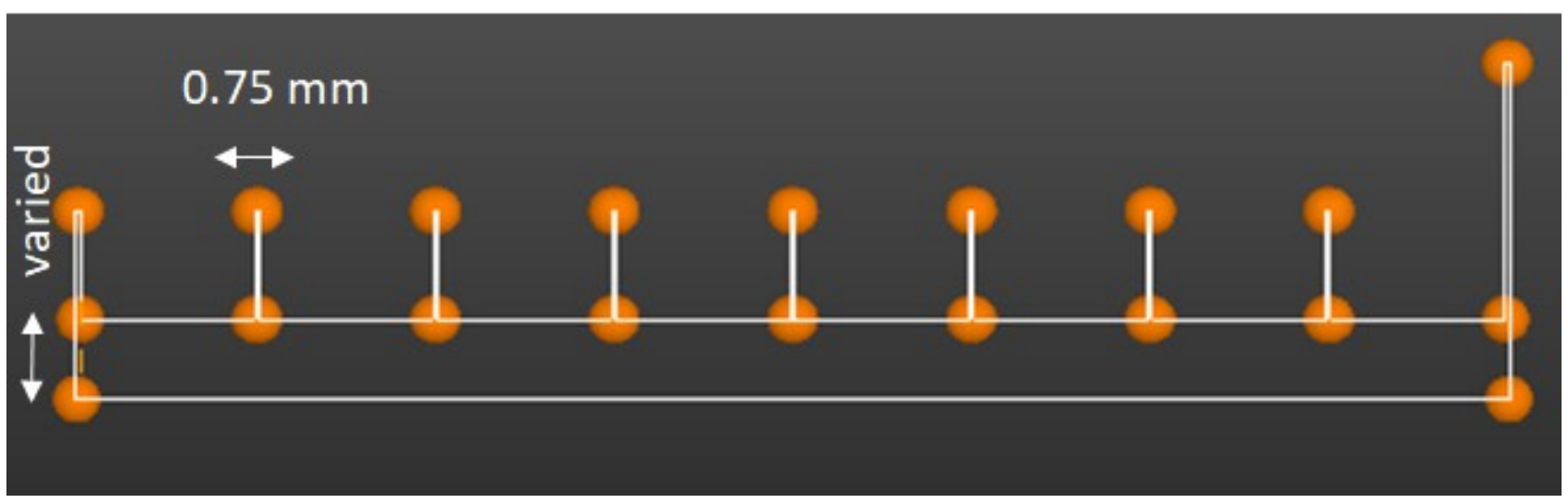

Figure 5. Vane profile of the main barrel design is shown for the conventional diffuse baseline vane design. 


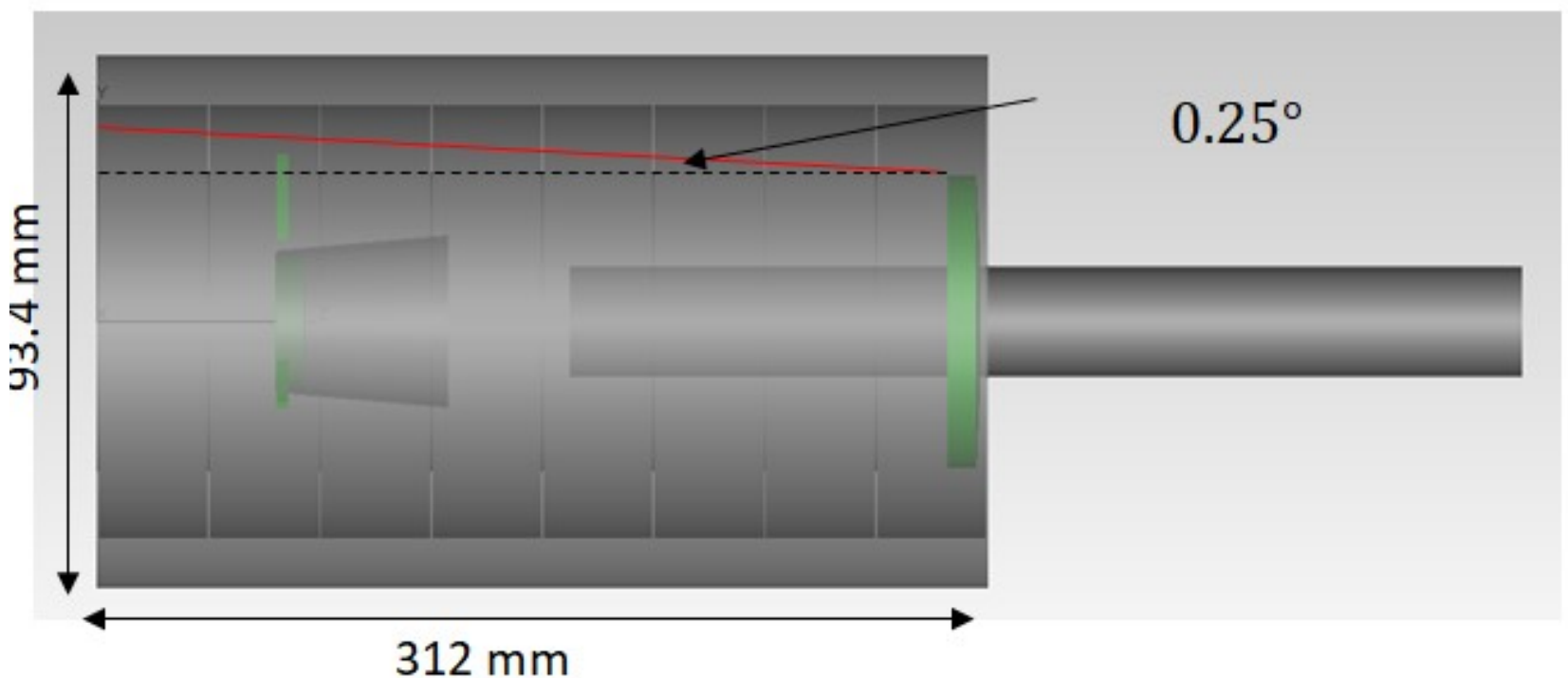

Figure 6. Conventional diffuse vane design with dimensions and a ray drawn at the edge of the FoV hitting the edge of the primary mirror.

Figure 7 shows the separation of the hot and critical ray areas and how these areas are determined by tracing rays at the extremes of the vane cavity from entrance aperture to each vane tip and from the edge of the primary mirror back to each vane tip. This procedure defines the vane cavity width to set the spacing for each vane.

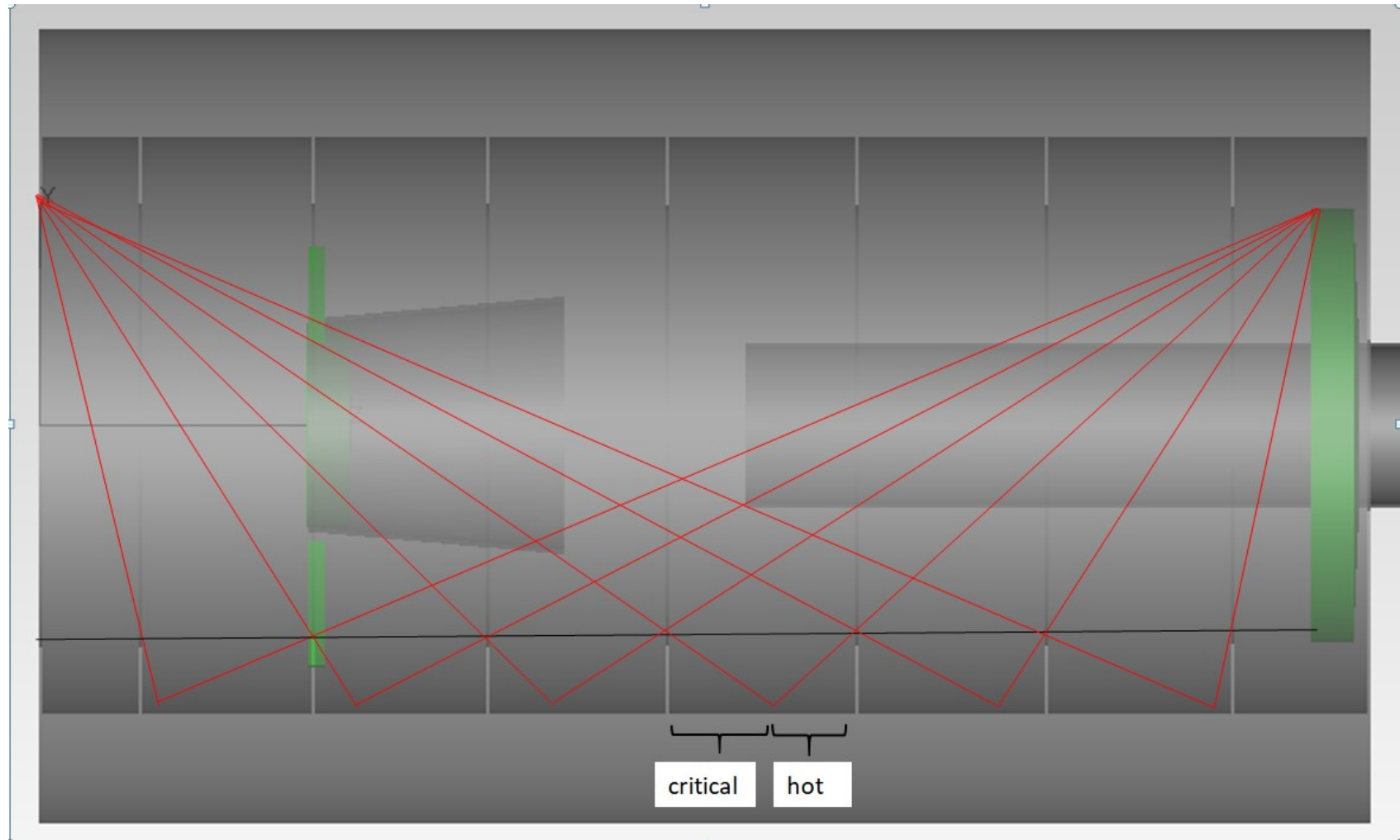

Figure 7. For the seven vane design the hot rays incoming into the baffle are separated from the critical zones for each vane design 


\subsection{Design of the Conventional Diffuse Seven Vane Design System with Unequal Vane Spacing}

The seven vane unequal spacing design investigates varied spacing and is similar to the seven vane design. The last larger disk at the end is once again the back of the main baffle which closes the cylindrically shaped main baffle. The inner radius of all seven vanes is still the same at $75.89 \mathrm{~mm}$ but the vanes are much less deep which is important for weight requirements for a space-based mission. This is where our default baseline design with equally vanes ends and cavity depth is optimized using software optimization. In this design, TracePro was used to define the spacing of the vane cavities and vane depth which were both determined by using the Downhill-simplex method in TracePro's 3D optimizer to minimize stray light by setting an operand to drive stray light flux to zero at the detector. Each orange control point shown on the top and bottom of each vane were equally changed to move vanes backward and forward to create an optimized design. This drove the cavity size so that larger vane cavities were created at the end of the main barrel baffle and smaller vane cavities near the entrance aperture. This function minimizes hot areas at the back of the baffle and larger hot areas at the beginning of the main barrel baffle. Figure 8 shows the starting point used to setup the baffle setup in TracePro Figure 9 shows the final optimized design.

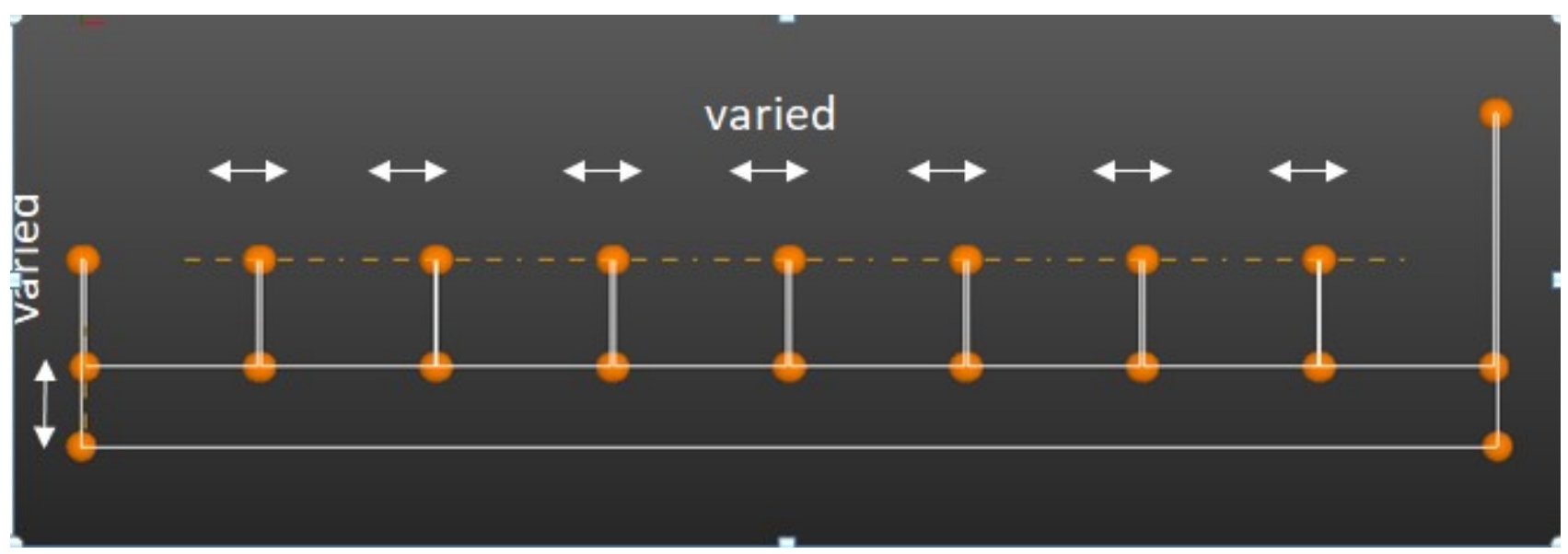

Figure 8. Vane profile of the main barrel design is shown for the conventional diffuse baseline vane design.

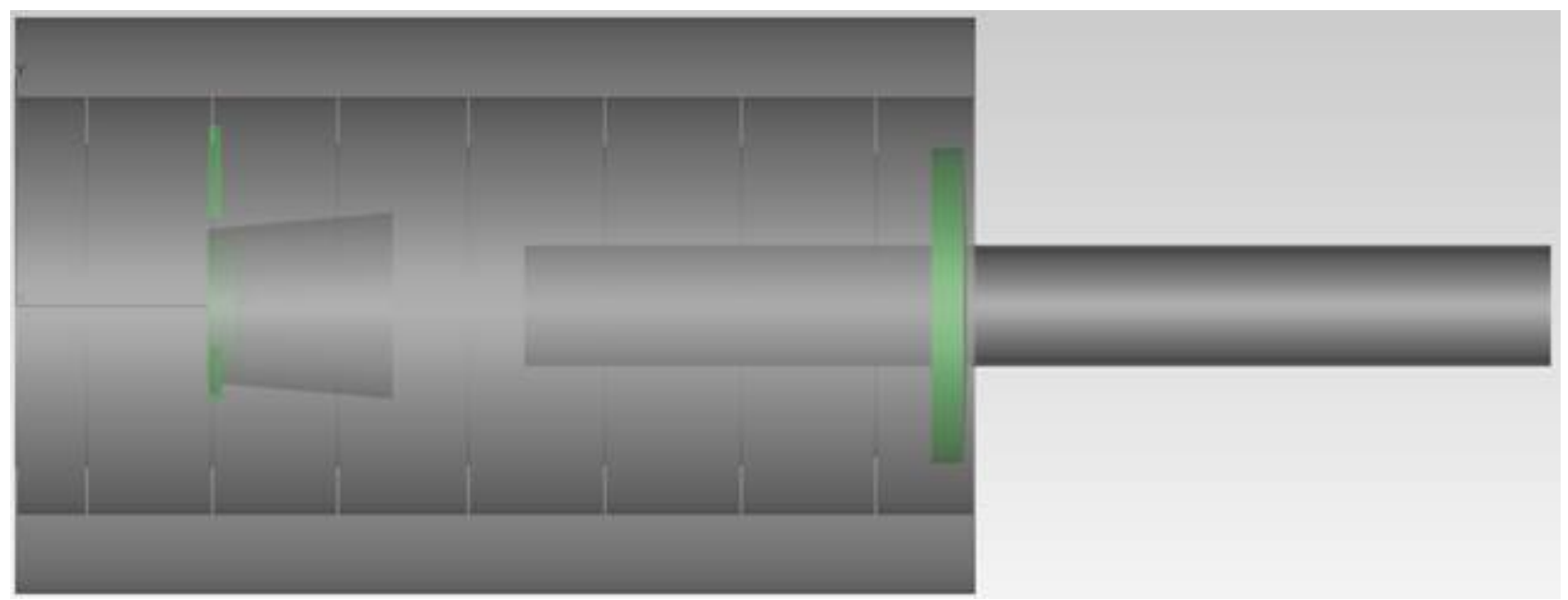

Figure 9. Final seven vane cavity design with unequal vane cavity spacing

\subsection{Design of the Conventional Diffuse Eight Vane Design System with Unequal Vane Spacing}

An eight vane design was investigated to determine if more vanes would help to reduce stray light. The only difference between this design and the seven vane design was the addition of an $8^{\text {th }}$ vane, while the same optimization was 
performed to find out the optimal vane depth and spacing. Figure 10 shows the starting point and Figure 11 shows the final design with hot and critical areas shown on the optimized baffle.

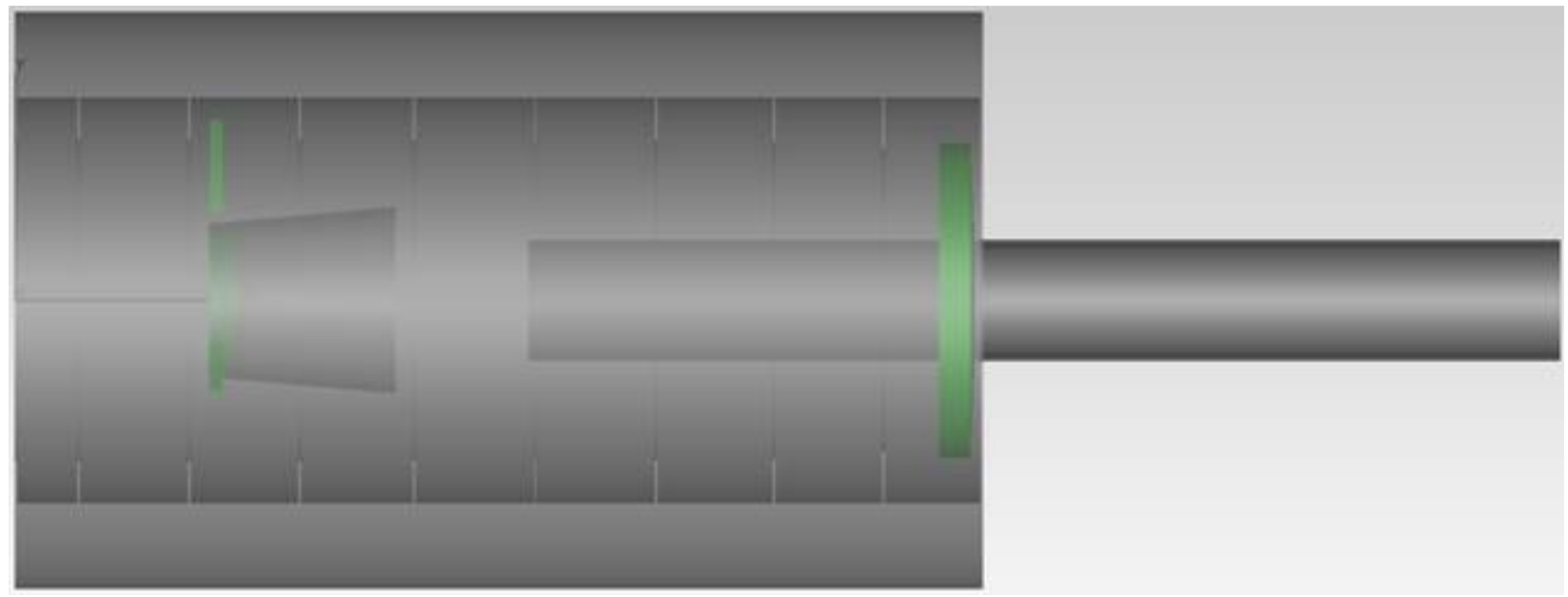

Figure 10. Starting design of the conventional eight vane unequal spaced diffuse baffle design

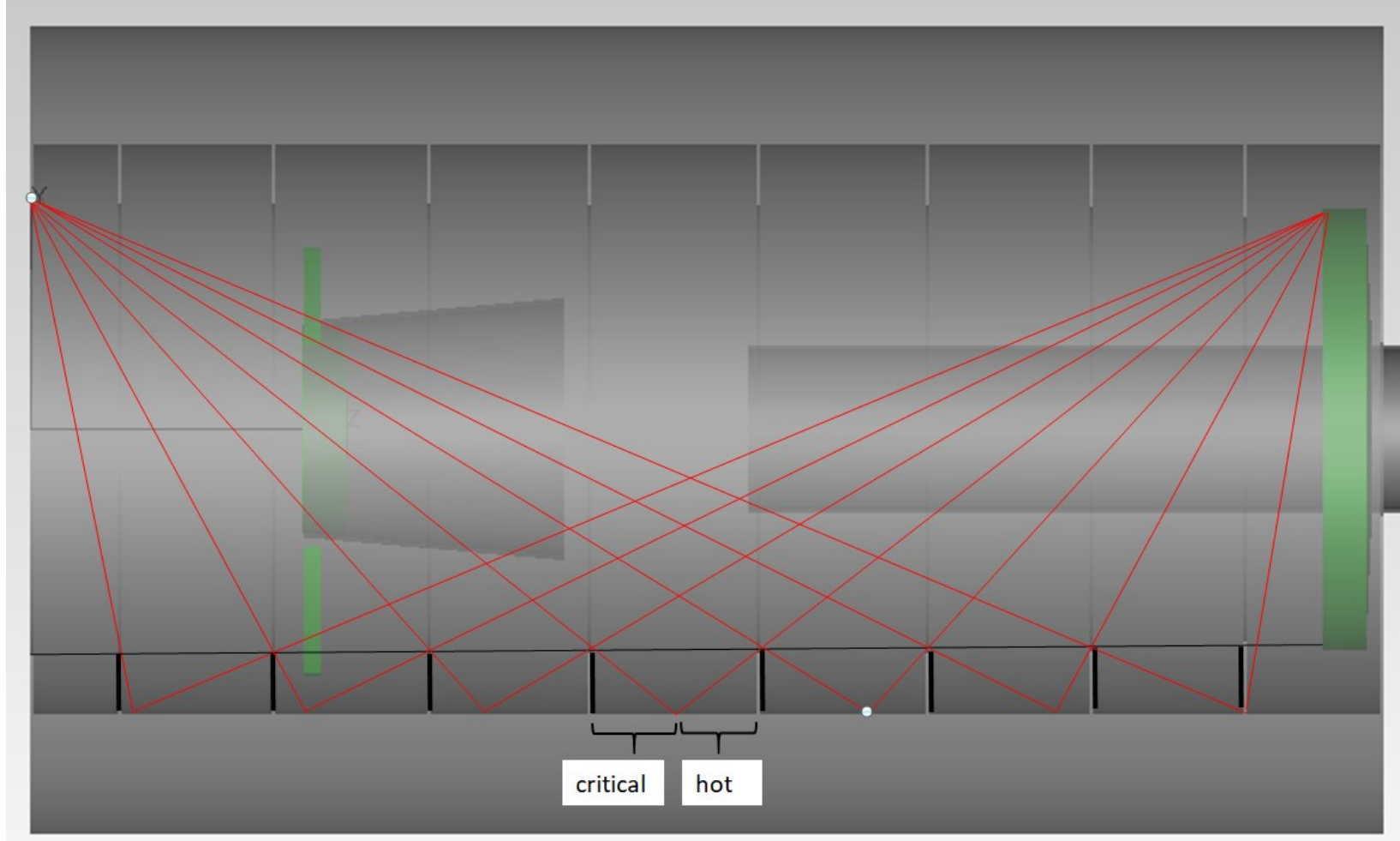

Figure 11. For the eight vane design, the hot rays incoming into the baffle are separated from the critical zones for each vane.

\subsection{Design of Two Vane Designs with Varied Vane Separations to Reduce Incoming Stray Light at 20 and 40 Degrees}

We investigated two more designs with varying vane separations, one optimized to reduce stray light for the 20 degrees incoming off-axis angle and one for the 40 degrees case. We used TracePro's optimizer in both cases to create a merit function that focused on reducing the stray light specifically at the 20 and 40 degrees incoming off-axis angle. We used the seven vane conventional design as the starting point. Figure 12 shows the Diffuse Variable Distance 20 Degree vane 
design after optimization, and Figure 13 shows the Diffuse Variable Distance 40 Degree design. Note that in both of these designs, the vane depth is much larger to stop stray light paths at the higher off-axis angles.

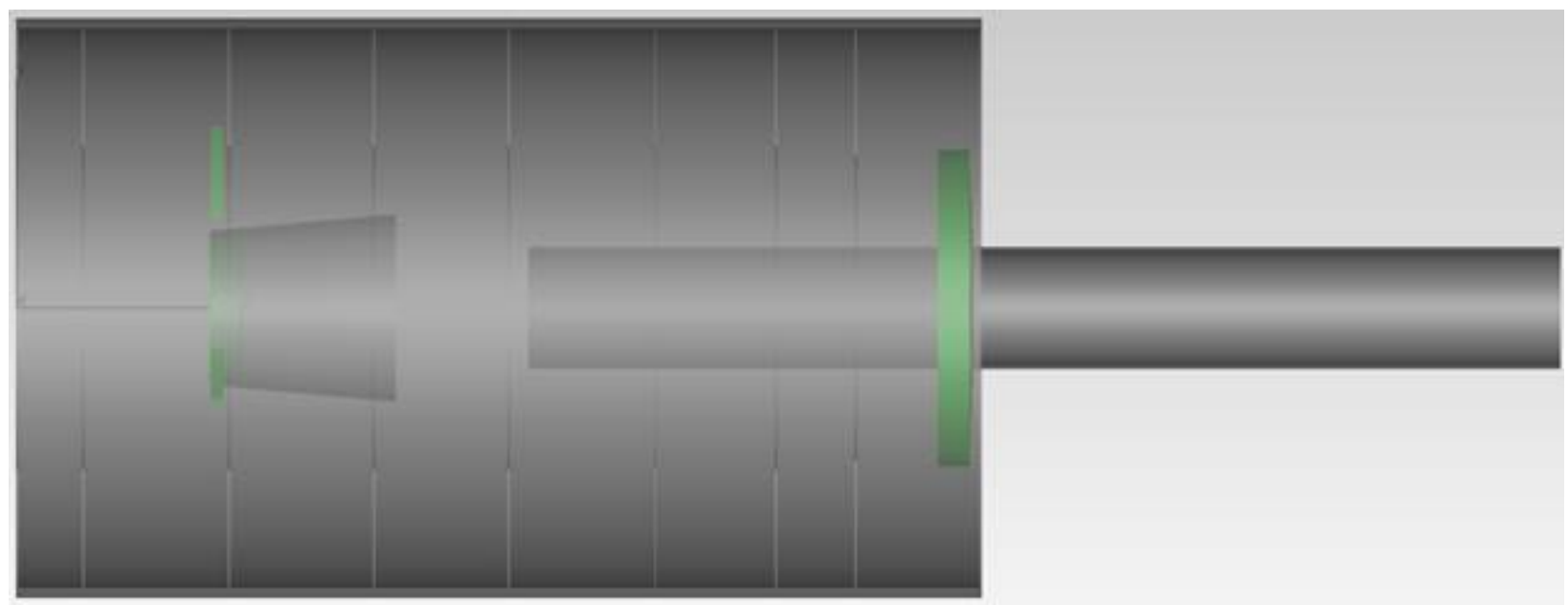

Figure 12. Diffuse Variable Distance 20 Degree vane design.

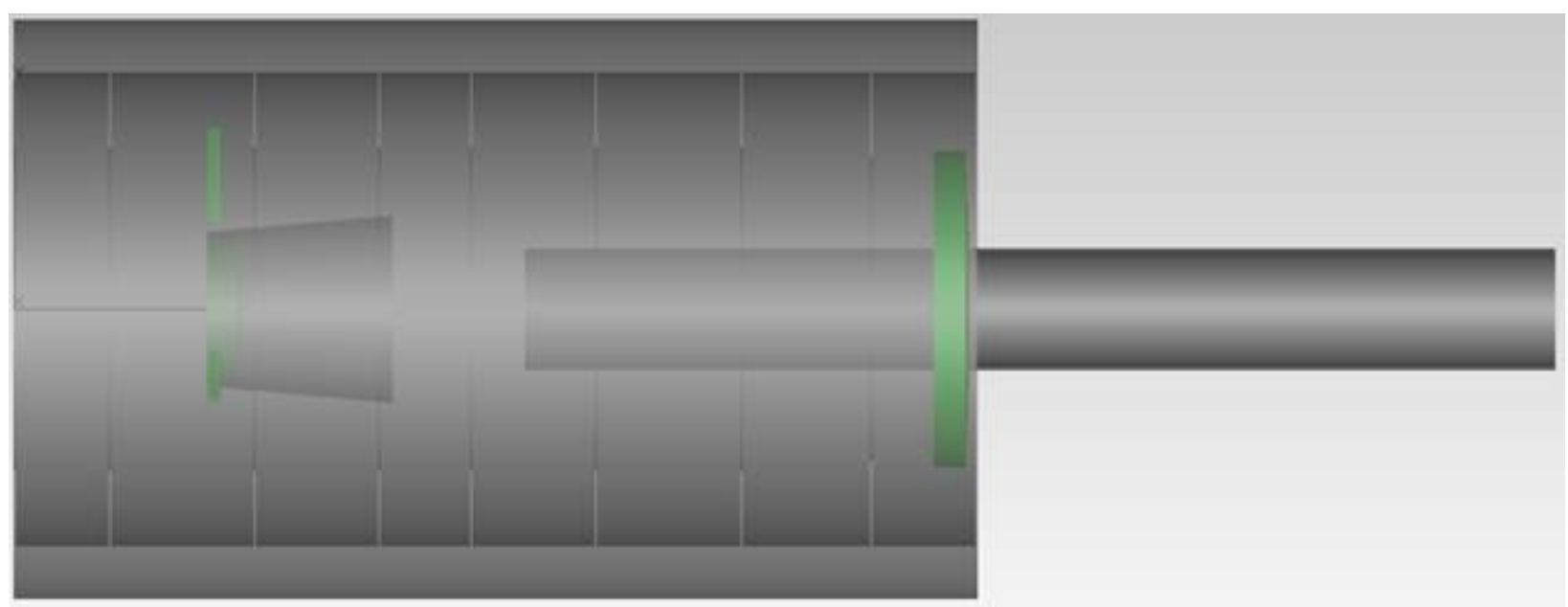

Figure 13. Diffuse Variable Distance 40 Degree vane design.

\subsection{Design of the Diffuse Curved Vane Design System}

We started with an initial diffuse flat curved design based on a variable spaced flat baffle design with a set of curved vanes with the back section angled to reject incoming light and the front section angled to throw light towards other back sections. Each of the vanes was defined as shown in Figure 14 with set end points and variable control points defined at the center of each section allowing movement as needed by the 3D optimizer in TracePro.

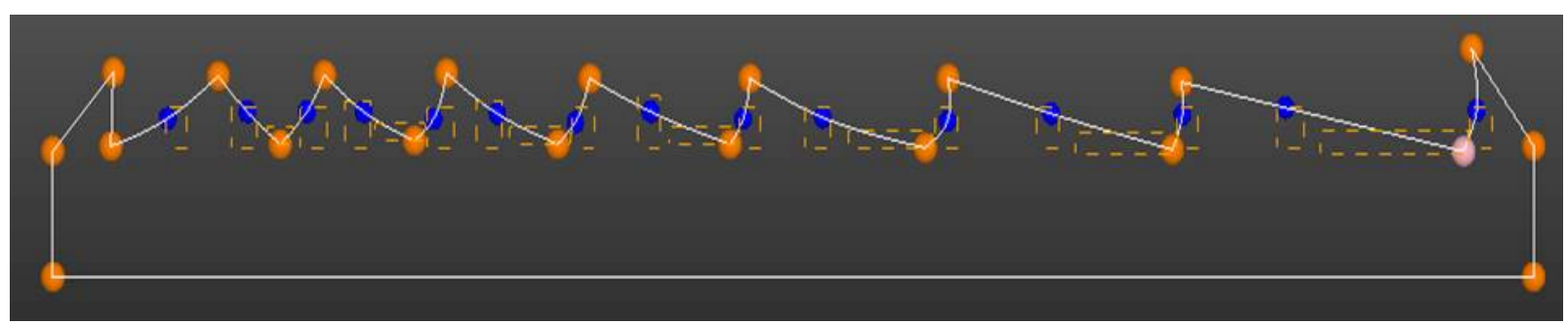

Figure 14. Starting point of the diffuse curved vane design with end points and control point shown. 
The finished design is shown below in Figure 15.

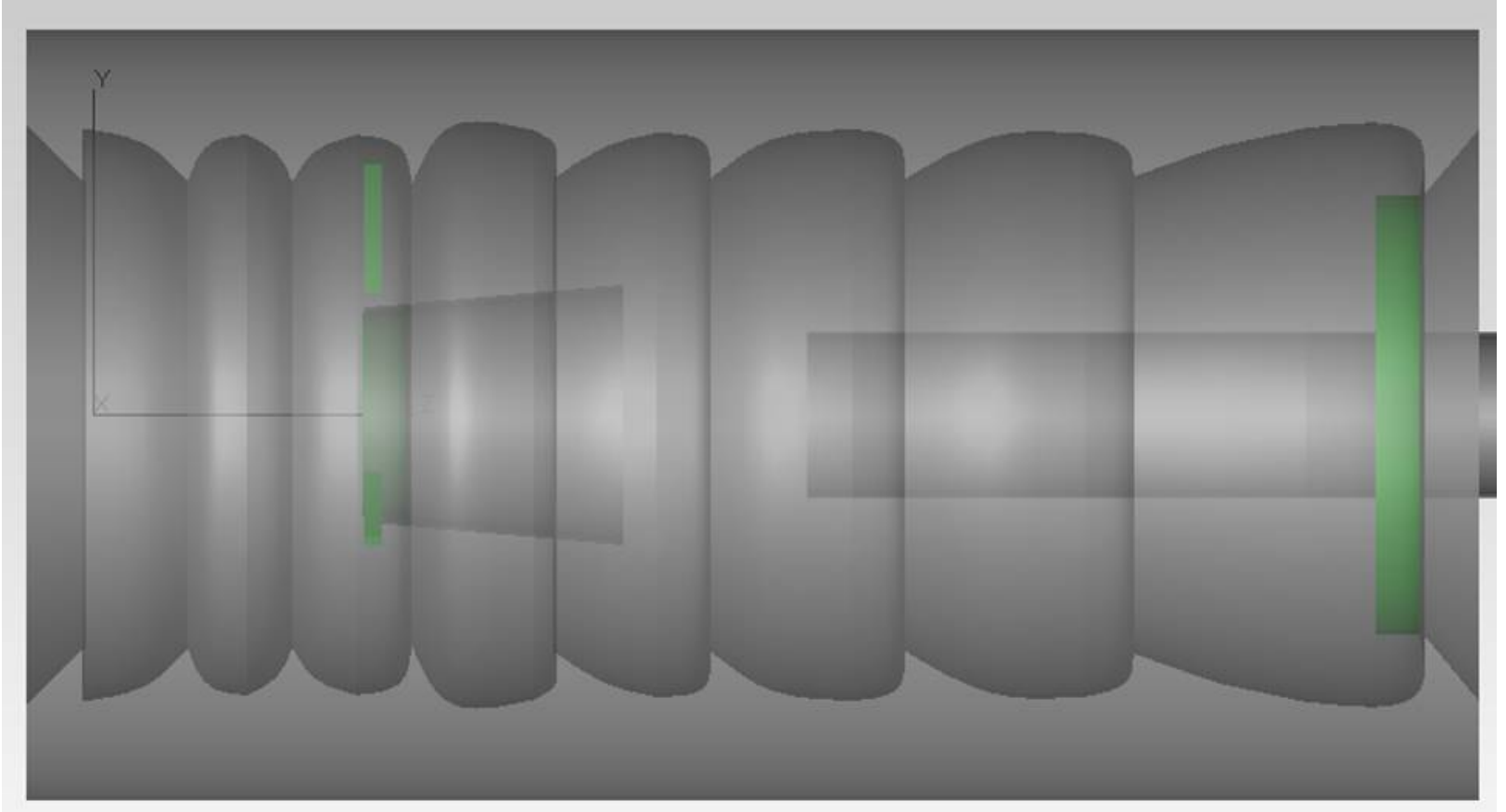

Figure 15. Final design of the diffuse curved vane design.

\section{SPECULAR BAFFLE DESIGNS}

There are three different specular vane baffle designs. We investigated a flat, a curved, and a design done by Stavroudis and $\mathrm{FoO}^{2}$, which was scaled to match the current Cassegrain design to provide a baseline for the specular designs.

\subsection{Design of the Flat Design System}

The specular flat design started initially as the seven straight varying vane design and was optimized using the TracePro 3D optimizer with the usual merit function to minimize stray light. The final optimized design is shown in Figure 16.

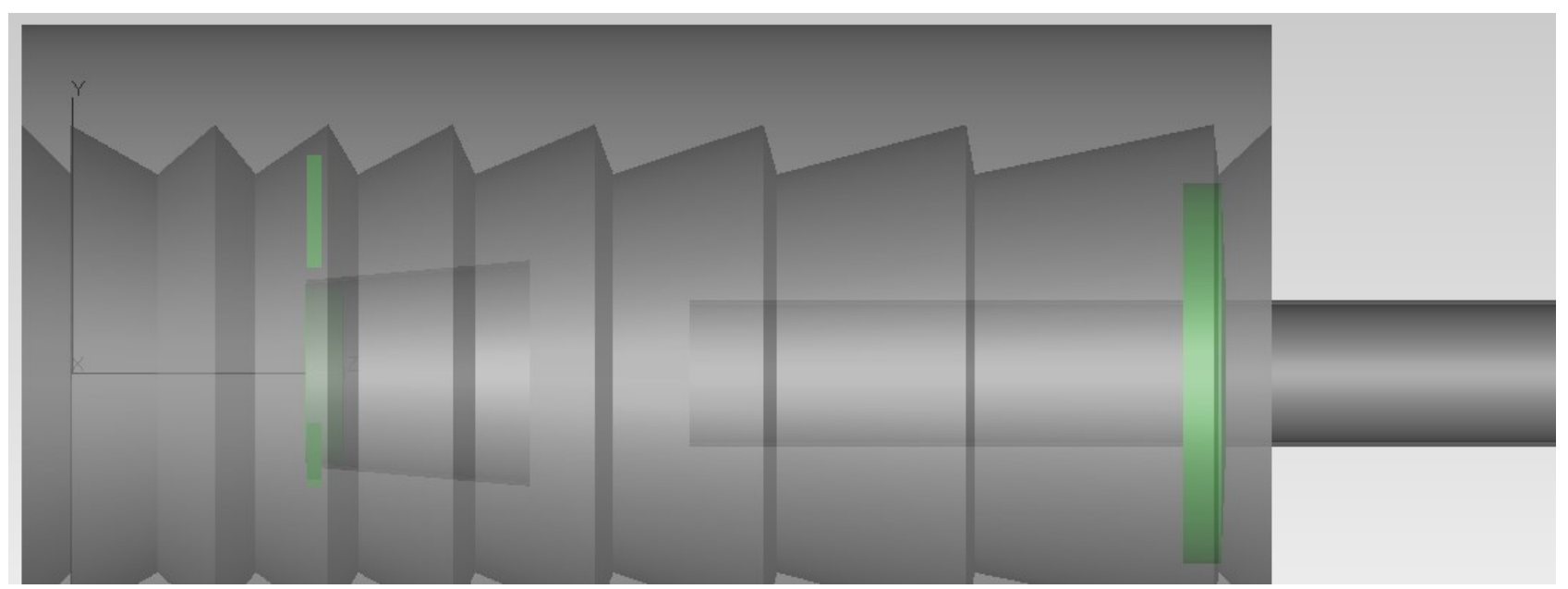

Figure 16. Final design of the flat specular design. 


\subsection{Design of the Curved Design System}

We started with an initial flat curved design based on a variable spaced flat baffle design with a set of curved vanes whose back section was angled to reject incoming light and front section angled to throw light towards the back section it faced. Each of the vanes was defined as shown in Figure 17 with set end points and variable control points defined at the center of each section that were allowed to move as needed by the 3D optimizer in TracePro.

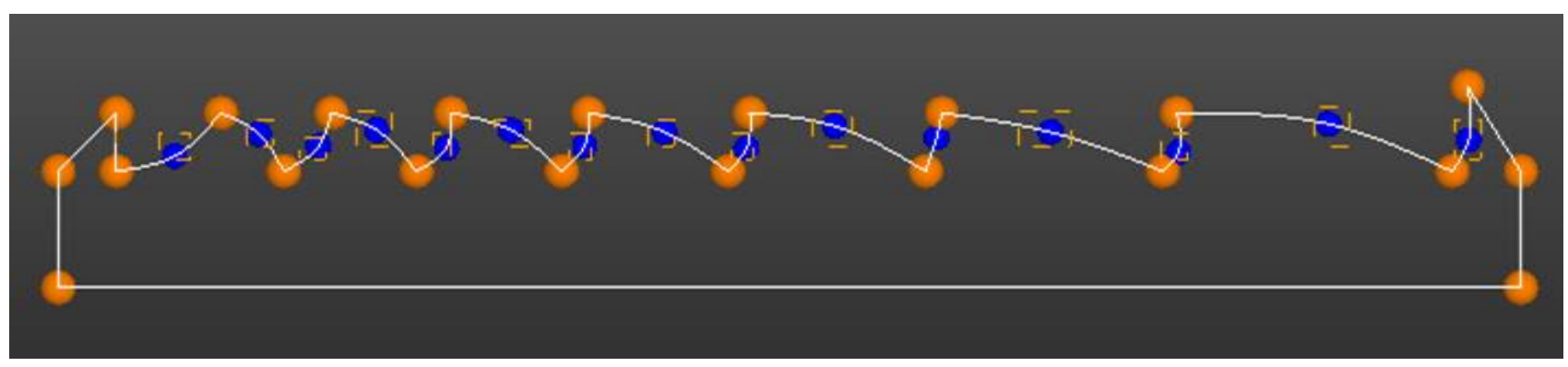

Figure 17. Starting point of the curved specular design with end points and control points shown.

The finished design is shown below in Figure 18.

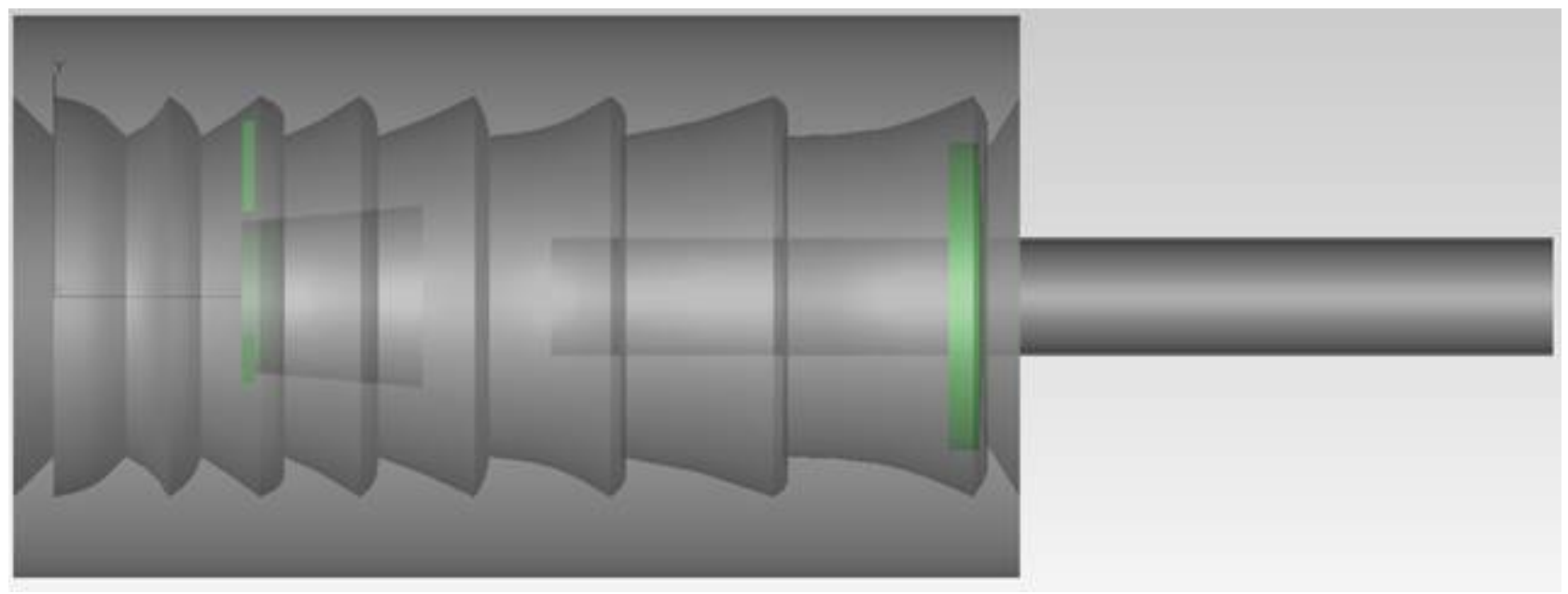

Figure 18. Final modified design after optimization.

\subsection{Design of the Stavroudis and Foo Curved Design System}

The design for the Stavroudis and Foo curved design baffle system is shown in Figure 19. This design was scaled by a factor of 1.08 to fit the Cassegrain system in OpticStudio we were using. This design was fitted using TracePro's 3D optimizer and then analyzed to find its PSNIT characteristics. The final revised design is shown in Figure 20. 


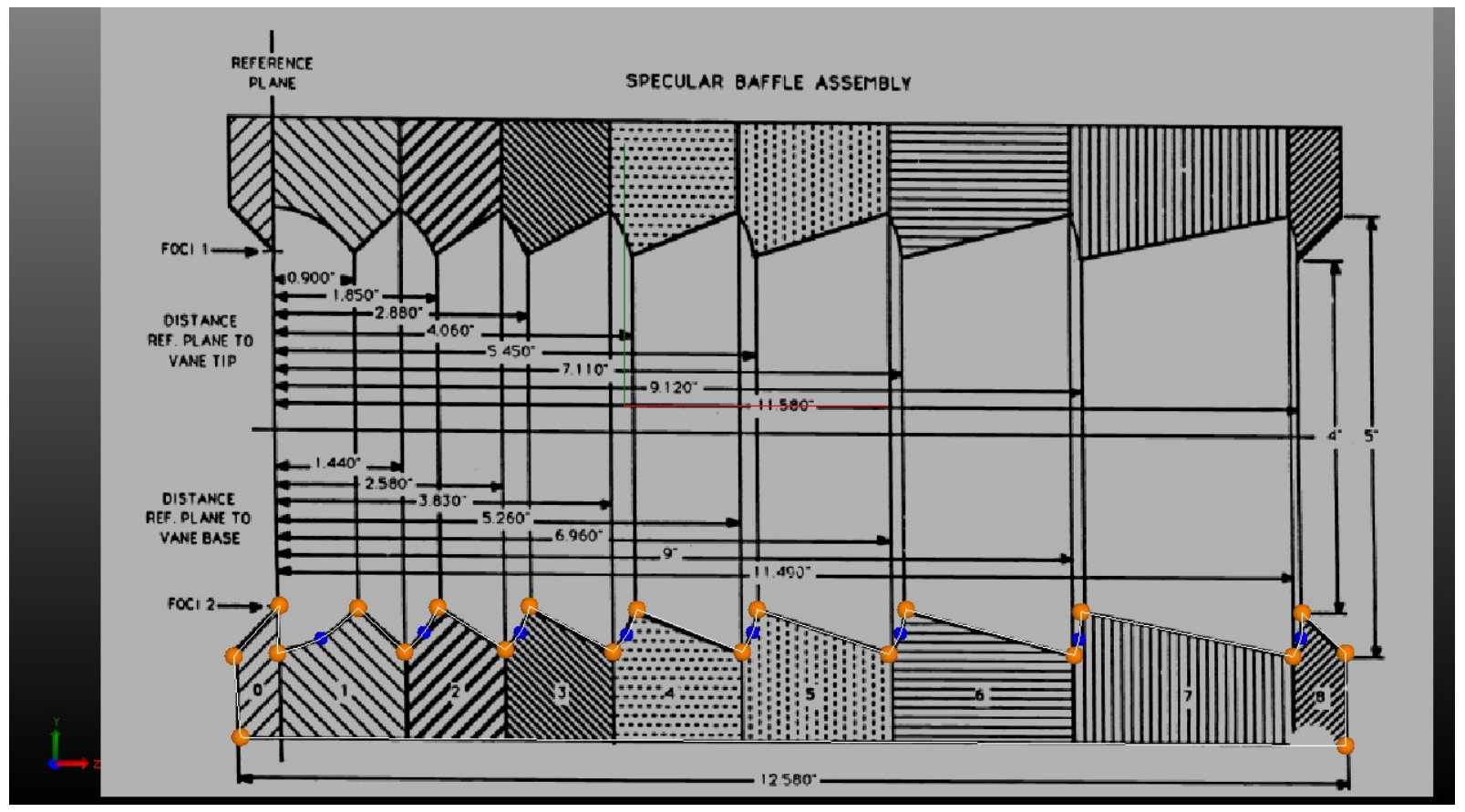

Figure 19. Design of the Stavroudis and Foo curved baffle design.

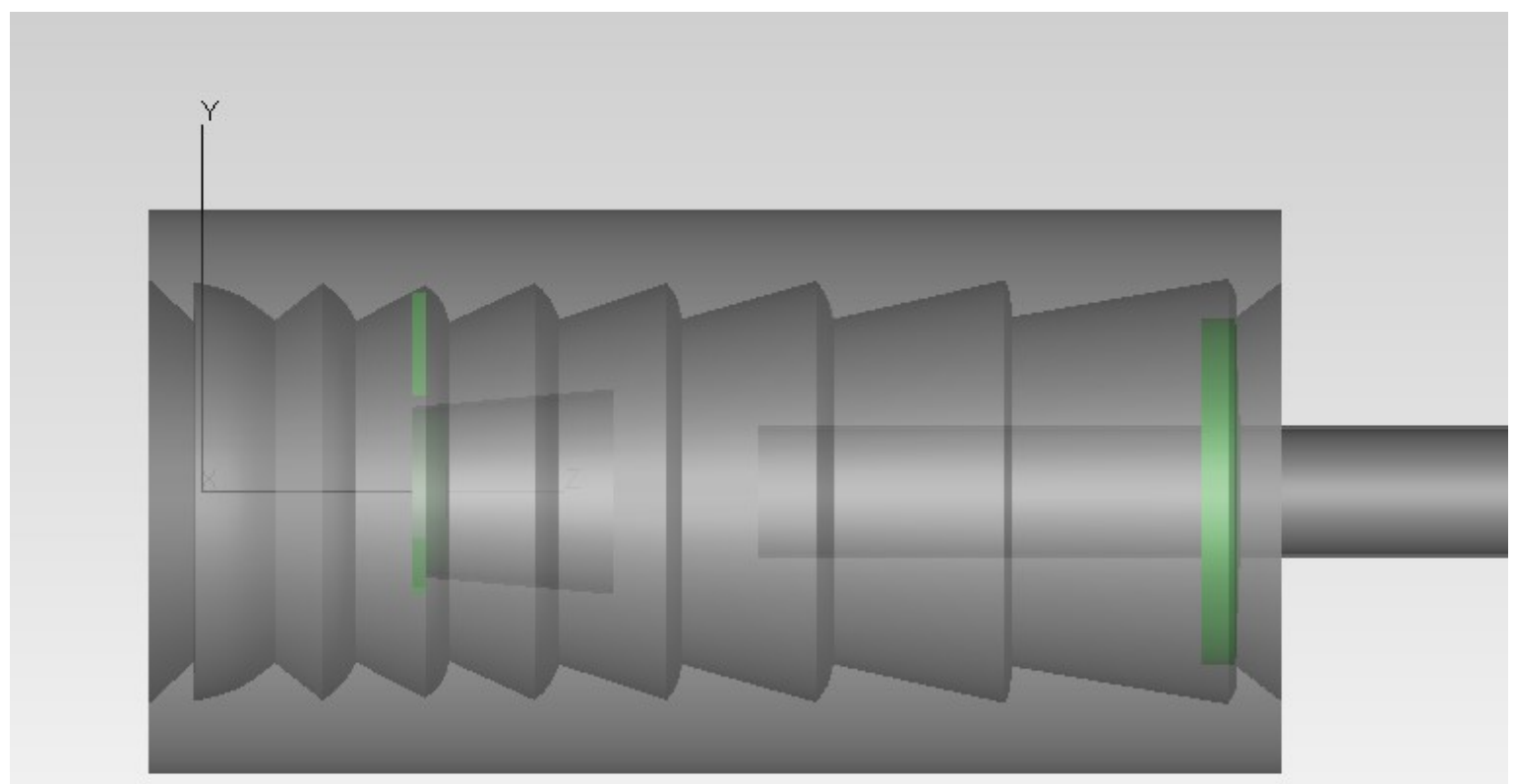

Figure 20. Design of the scaled Stavroudis and Foo curved baffle design as analyzed in TracePro. 


\section{DESIGN OF STRAY LIGHT PATHS THAT WERE OPTIMIZED OUT OF THE FINAL DESIGN}

In this section, we look in-depth at the top stray light path in the diffuse baseline design. This is a large stray light path at 10 degrees due to its equally spaced vane design. The major path stray light path for the incoming 10 degrees off-axis angle scatters light from the back of the main baffle to the detector by reflecting off the secondary mirror as shown in Figure 21. A last vane can be extended in height to block this stray path or an $8^{\text {th }}$ vane can be added to block this path. This method was implemented for all the other optimized diffuse baffle designs to remove this stray light path.

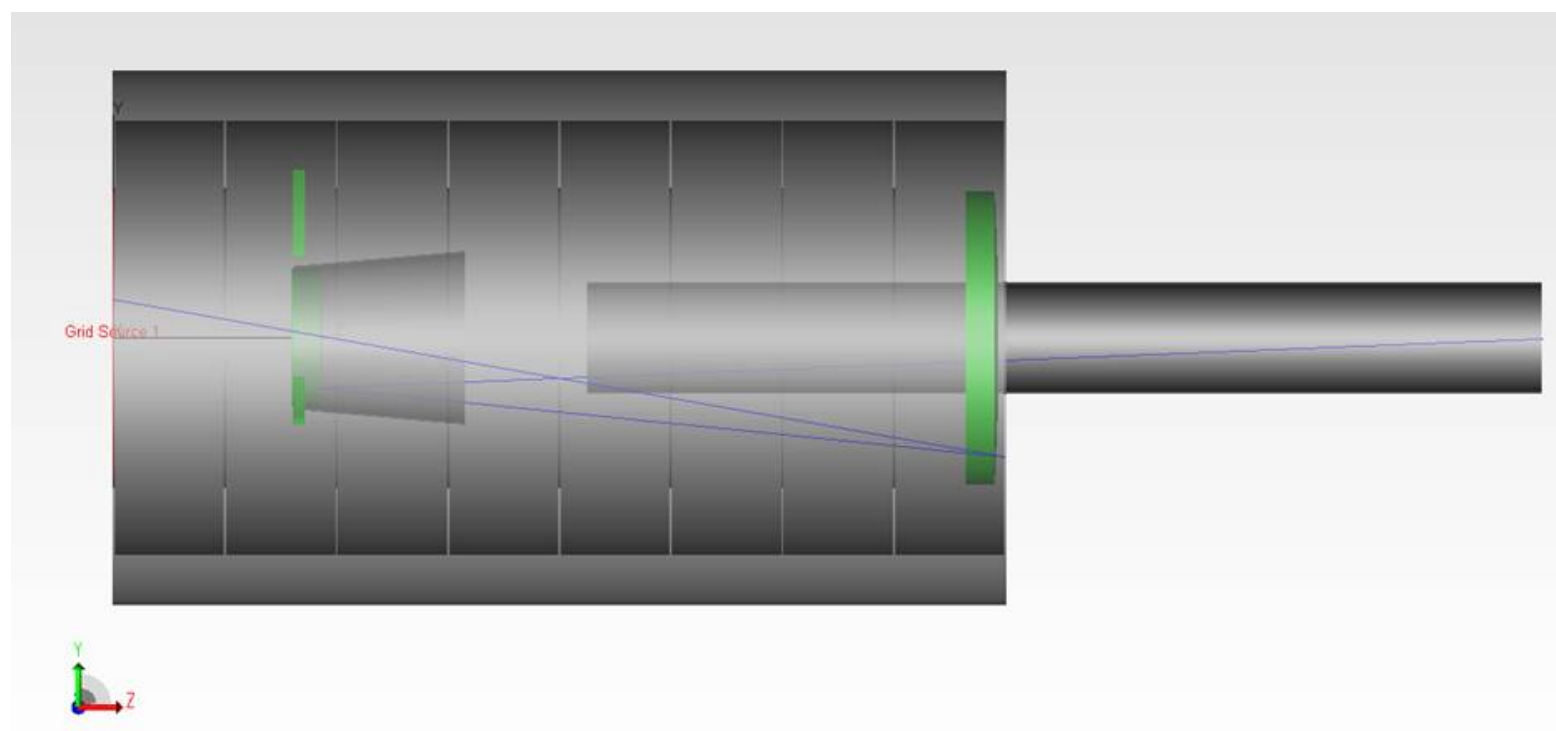

Figure 21. Stray light path from at the 10 degrees off-axis angle shown with a ray drawn to depict the path.

The largest stray light path for the 15 degrees incoming off-axis path scatters light from the end of the primary baffle and then scatters this light to the inner surface of the primary baffle which reflects light towards the detector. Figure 22 shows this stray light path. After this path was found in all optimized versions of the diffuse baffle vane design black diffuse paint was applied to the inside of the primary baffle to lower stray light from these type of paths. All final optimized versions have diffuse black on the inside of the secondary and primary baffles.

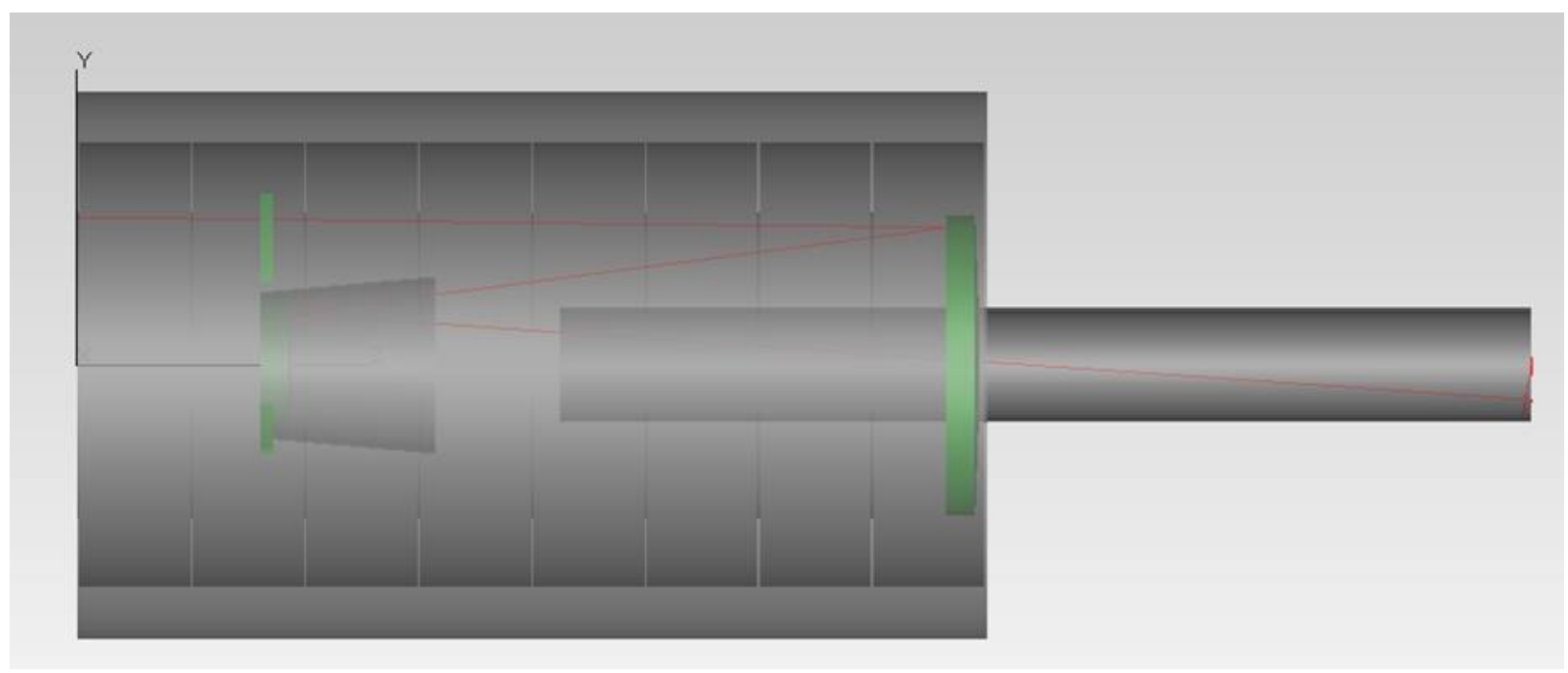

Figure 22. Stray light path from at the 15 degrees off-axis angle shown with ray drawn to depict path. 


\section{RESULTS AND IN-DEPTH DISCUSSION OF THE PARAMETERS USED FOR THE SOFTWARE SIMULATIONS}

The PSNIT is plotted versus the incoming off-axis angle for all nine vane designs in Figure 23. Each of the optimized vane designs had more than 200 iterations to drive the merit function as close to zero as achievable. The merit function used was quite simple: an operand was set to drive the power reaching the detector outside the FoV to zero. The closer the PSNIT is to zero, the better the system performed. The figure is color coded for easy visualization of each path with lower PSNIT depicting better design since we want the lowest PSNIT possible. Importance sampling was used as a variance reduction technique to ensure stray light reached the detector from baffles to optics and inner baffles.

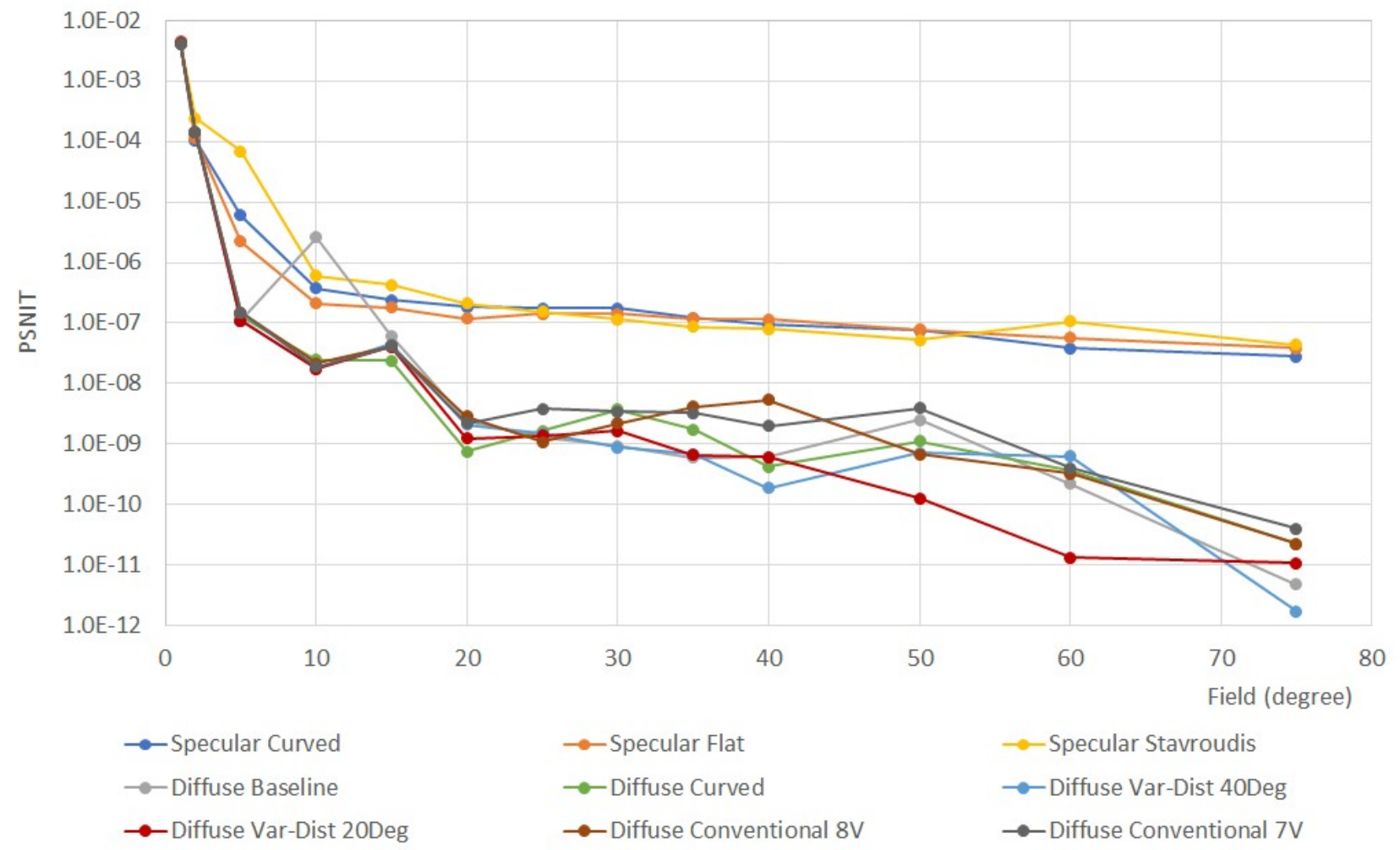

Figure 23. Plot of the PSNIT for all nine vane designs. Each design is color coded.

\section{CONCLUSIONS}

For this particular Cassegrain telescope system, the specular design PSNITs were on the average 1.5 orders of magnitude worse than the best diffuse system. The best performing configuration was the Diffuse Variable Distance 20 degrees design. The best specular design was the specular curved design which has the best performance from 40 degrees out to 75 degrees. We know that in the low infrared at $980 \mathrm{~nm}$, black anodized coatings start to behave like reflectors, and here is where a curved specular design can start to play an interesting alternative to black diffuse coating designs.

For certain systems, the conventional design's vane separations are close to constant, so a fixed-separation vane design is a good starting point as the conventional design. Looking at the results, it is evident that the best designs were generated using TracePro's optimization algorithm to reduce stray light.

The specular baffle design all have higher stray light but reduced weight and have much less thermal issues due to absorbed heat from the diffuse paint. Some other findings are:

1. Most specular baffles have similar performance in PSNIT, while the flat-vaned designs are easier to manufacture and test. 
2. The dominant issues in the specular baffle designs are the residual scattering from the vanes and the scattering from the inner structures (e.g. secondary baffle)

\section{ACKNOWLEDGEMENT}

This work was partially supported by the NSF Grant 1607358 .

\section{REFERENCES}

[1] Wikipedia, en.wikipedia.org/wiki/Stray light, retrieved August 1, 2019

[2] Gary Peterson, "Stray light calculation methods with optical ray trace software", Proc. SPIE 3780, Optical Design and Analysis Software, (27 September 1999)

[3] Orestes N. Stavroudis, Leslie D. Foo, "System of reflective telescope baffles", SPIE Published in Volume 33, Issue 03, March 1994 